\title{
Circulação do vírus respiratório sincicial humano em cinco Estados da Região Amazônica brasileira: primeira descrição do genótipo ON1 no Pará
}

\author{
Human respiratory syncytial virus circulation in five States of the Brazilian Amazon \\ Region: first description of the ON1 genotype in Pará
}

Vinicius Maia dos Santos', Jessylene de Almeida Ferreira', James Ferreira Lima', Luana Soares Barbagelata', Edna Maria Acunã de Souza', Maryelle dos Santos Gonçalves', Edivaldo Costa Sousa Júnior', Igor Brasil Costa', Mirleide Cordeiro dos Santos', Rita Catarina Medeiros Sousa ${ }^{1,2}$, Wyller Alencar de Mello'

' Instituto Evandro Chagas, Seção de Virologia, Ananindeua, Pará, Brasil

2 Universidade Federal do Pará, Belém, Pará, Brasil

\begin{abstract}
RESUMO
OBJETIVO: Realizar a detecção e caracterização das cepas de vírus respiratório sincicial humano (VRSH), nos casos de infecção respiratória aguda (IRA), circulantes nos estados brasileiros do Acre, Amapá, Amazonas, Pará e Roraima, no ano de 2015. MATERIAIS E MÉTODOS: Foram coletadas 1.082 amostras de aspirado de nasofaringe e swab combinado narina e garganta de pacientes de diferentes gêneros e faixas etárias com IRA e submetidas à qRT-PCR para VRSH. As amostras positivas foram inoculadas em cultura celular HEP-2 e as que apresentaram efeito citopático foram submetidas a três etapas: extração do RNA viral, amplificação do gene $G$ pela RT-PCR e sequenciamento genético. RESULTADOS: Das 1.082 amostras, 57 (5,3\%) foram positivas para VRSH, sendo $38(66,7 \%)$ de pacientes de 0 a 4 anos de idade. A circulação predominou entre março e julho, período de transição climática na Região. Apenas no Acre, Amazonas e Pará foram detectadas amostras positivas, 15 (26,3\%), 23 (40,4\%) e 19 (33,3\%), respectivamente. O efeito citopático foi avaliado em 45 (78,9\%) amostras, nas quais foram identificados os subgrupos: 40 (88,9\%) do VRSH-B com genótipo BA e cinco $(11,1 \%)$ do VRSH-A do genótipo ON1. CONCLUSÃO: Este estudo revelou uma taxa de infecção viral relevante em crianças de 0 a 4 anos de idade. A circulação viral ocorreu no Acre, Amazonas e Pará durante o período de mudança climática. Foi notória a ocorrência dos genótipos $B A$ e $O N 1$, sendo a primeira vez que se comprova a circulação do ON1 no Pará.
\end{abstract}

Palavras-chave: Vírus Sinciciais Respiratórios; Pesquisa sobre Serviços de Saúde; Biologia Molecular; Genótipo.

\begin{abstract}
OBJECTIVE: To detect and characterize the Human respiratory syncytial virus (HRSV) strains in cases of severe acute respiratory infection (SARI) circulating in Brazilian States of Acre, Amapá, Amazonas, Pará, and Roraima in 2015. MATERIALS AND METHODS: A total of 1,082 samples of nasopharyngeal aspirate and combined nasal-throat swabs of patients of different sex and age groups with SARI and submitted to gRT-PCR for HRSV. Positive samples were inoculated in HEP-2 cell cultures and those presenting cytopathic effect were submitted to three steps: extraction of RNA viral load, G-gene amplification by RT-PCR and genetic sequencing. RESULTS: Of 1,082 samples, 57 (5.3\%) were positive for HRSV, $38(66.7 \%)$ were from patients from 0 to 4 years old. Viral circulation predominated between March and July, period of climate changes in the Region. Only in Acre, Amazonas, and Pará positive samples were detected, 15 (26.3\%), 23 (40.4\%), and $19(33.3 \%)$, respectively. The cytopathic effect was evaluated in $45(78.9 \%)$ samples with the following viral subgroups: 40 (88.9\%) of HRSV-B with BA genotype, and five (1 1.1\%) of RSV-A of ON1 genotype. CONCLUSION: This study showed a relevant viral infection rate in children 0 to 4 years old. Viral circulation occurred in Acre, Amazonas, and Pará during the climatic changes period. The circulation of the genotypes BA and ON1 was significant, and the first time that the circulation of ONI in Pará State was confirmed.
\end{abstract}

Keywords: Respiratory Syncytial Virus; Research on Health Services; Molecular Biology; Genotype.

\footnotetext{
Correspondência / Correspondence:

Vinicius Maia dos Santos

Instituto Evandro Chagas, Seção de Virologia

Rodovia BR-316, km 7, s/n. Bairro: Levilândia. CEP: 67030-000 - Ananindeua, Pará, Brasil - Tel.: +55 (91) 98140-8469 / $3214-2024$

E-mail:vinicius.maia.tst@gmail.com
} 


\section{INTRODUÇÃO}

Mostrando um grande espectro de manifestações clínicas, as infecções respiratórias são conhecidas por causar altas taxas de morbidade, gerando o aumento da demanda ambulatorial e em casos mais graves, internações hospitalares ${ }^{1,2}$.

A infecção respiratória aguda (IRA) é conhecida como a manifestação mais frequente entre as doenças do trato respiratório e é causada expressivamente por agentes virais, principalmente pelo vírus influenza e o vírus respiratório sincicial humano $(\mathrm{VRSH})^{3}$. Assim, - VRSH é responsável por aproximadamente 15 a $40 \%$ dos casos pediátricos de pneumonia/bronquiolite relatados ${ }^{4}$.

O VRSH é um vírus pleomórfico, envelopado, com genoma não segmentado de RNA de cadeia simples, de polaridade negativa, com aproximadamente 15.200 nucleotídeos que codificam 11 proteínas ${ }^{5}$. Esse vírus pertence à ordem Mononegavirales, família Pneumoviridae, gênero Orthopneumovirus. Considerando a região hipervariável 2 da glicoproteína $G^{6}$, o VRSH é classificado em dois subgrupos (VRSH-A e VRSH-B). Até o presente momento, foram descritos 14 genótipos de VRSH-A, incluindo GA1-GA77, SAA ${ }^{8}$, NA1-NA2 ${ }^{9}, \mathrm{ON}^{10}{ }^{10}, \mathrm{CB}-\mathrm{A}^{11}{ }^{1}, \mathrm{NA3}$ e NA4 ${ }^{12}$, e 25 genótipos para VRSH-B, classificados em GB1-GB513,14, $\mathrm{SAB} 1-\mathrm{SAB} 4^{8,15}$, URU1 URU2 ${ }^{16}, \mathrm{BA} 1-\mathrm{BA} 12^{17,18}, \mathrm{CB} 1$ e $B A-C^{19}$.

A variabilidade genética e antigênica entre os subgrupos, bem como entre as cepas do mesmo subgrupo, é mais enfatizada na glicoproteína $\mathrm{G}^{20,21}$, com divergência na sequência aminoacídica que pode atingir $47 \%$ entre os subgrupos ${ }^{19}$. A evolução antigênica da glicoproteína $G$ causa reinfecções pelo VRSH e cria interesse substancial em diferentes estudos $^{18,22,23}$.

A presente investigação objetivou avaliar os aspectos epidemiológicos e moleculares relacionados à circulação de cepas do VRSH associadas a casos de IRA em cinco Estados da Amazônia brasileira, no período de janeiro a dezembro de 2015.

\section{MATERIAIS E MÉTODOS}

\section{AMOSTRAS CLÍNICAS}

Este estudo foi realizado com 1.082 espécimes clínicos pertencentes a indivíduos de ambos os gêneros, de diferentes idades e diagnosticados clinicamente com IRA. Dessas amostras, $424(39,2 \%)$ pertenciam a crianças de 0 a 4 anos de idade, 156 (14,4\%) a crianças de 5 a 14 anos, 90 (8,3\%) a jovens de 15 a 24 anos, $278(25,7 \%)$ a adultos de 25 a 59 anos e $134(12,4 \%)$ a idosos com idade igual ou superior a 60 anos.

Todos os pacientes foram atendidos ambulatoriamente em unidades de saúde localizadas nos Estados da Amazônia brasileira (Acre, Amapá, Amazonas, Pará e Roraima), de janeiro a dezembro de 2015. Nesse cenário, 370 (34,2\%) amostras foram oriundas do Acre, 170 (15,7\%) do Amazonas, 496
$(45,9 \%)$ do Pará, 36 (3,3\%) de Roraima e 10 (0,9\%) do Amapá.

A coleta do espécime clínico foi realizada em pacientes com diagnóstico clínico de IRA, mediante aspirado de nasofaringe, utilizando bomba a vácuo acoplada a um tubo coletor contendo meio de transporte (Hanks e gelatina a $0,5 \%$ ) ou swab combinado narina e garganta. Posteriormente as amostras foram encaminhadas para o Laboratório de Vírus Respiratórios do Instituto Evandro Chagas, sob refrigeração $\left(4^{\circ} \mathrm{C}\right)$.

\section{EXTRAÇÃO DO RNA VIRAL (RNAV)}

O RNAv foi extraído das amostras de secreção respiratória dos pacientes investigados utilizando 0 kit comercial QIAamp ${ }^{\circledR}$ Viral RNA Mini Kit (QIAGEN, Renânia do Norte-Vestfália, Alemanha), seguindo as instruções do fabricante. $\bigcirc$ RNA eluído foi armazenado a $-70{ }^{\circ} \mathrm{C}$ ou imediatamente usado para reação da transcriptase reversa, seguida da reação em cadeia de polimerase em tempo real (qRT-PCR).

\section{DETECÇÃO DO GENOMA VIRAL}

A detecção do genoma viral foi realizada por qRT-PCR usando o kit comercial SuperScript III ${ }^{T M}$ One-stepqRT-PCR with Platinum Taq ${ }^{\circledR}$ (Invitrogen Life Technologies, Califórnia, EUA) para um volume final de $25 \mu \mathrm{L}$, com $5 \mu \mathrm{L}$ de RNAv, Master Mix PCR 2X, SuperScript ${ }^{\text {TM }}$ III RT/Platinum ${ }^{\circledR}$ TaqMix, iniciadores, a 40 nM (VRSH senso: 5' GCT CTT AGC AAA GTC AAG TTR AAT GAT ACA 3'; VRSH antissenso: 5' GTT TTT GCA CAT CAT AAT TRG GAG T) e sonda a $10 \mathrm{nM}$ (5' CTG TCA TCY AGC AAA TAC ACT AT 3') marcado com corante reporter de 6-carboxi-fluoresceína (FAM) e corante de quimioterapia com 6-carboxi-tetrametil-rodamina (TAMRA). A reação de amplificação foi realizada primeiro por uma transcrição reversa a $48{ }^{\circ} \mathrm{C}$ em 30 min, seguindo a ativação da Taq polimerase a $95^{\circ} \mathrm{C}$ em 10 min e a amplificação pela PCR composta por 45 ciclos de $95{ }^{\circ} \mathrm{C}$ por $15 \mathrm{~s}$ e $60{ }^{\circ} \mathrm{C}$ por $1 \mathrm{~min}$, sendo o protocolo fornecido pelo Centers for Diasease Control and Prevention ${ }^{24}$.

\section{PROPAGAÇÃO VIRAL EM CULTURA CELULAR}

As amostras clínicas positivas para VRSH por qRT-PCR foram submetidas ao cultivo viral na linhagem de células HEp-2 (carcinoma epidermoide da laringe humana) durante um período de observação de 12 dias. Nas amostras que apresentaram efeitos citopáticos, a coleta do sobrenadante foi realizada para a realização da caracterização molecular.

\section{AMPLIFICAÇÃO DO GENE G}

Para a caracterização genética do VRSH, uma amplificação do gene responsável para codificar a glicoproteína $G$ foi feita a partir do RNA viral extraído do sobrenadante da cultura celular infectada, utilizando a técnica RT-PCR em um único tubo com o kit comercial SuperScriptTM"II One-Step RT-PCR Platinum Taq HiFi (Invitrogen Thermo Scientific, Califórnia, EUA) e iniciadores específicos para o gene $G$ do VRSH-A (VRSH-A senso: 5'GCA AAC ATG TCC AAA AAC 
AAG 3'; VRSH-A antissenso: 5'GTT ATG ACA CTG GTA TAC CAA CC 3') para a amplificação de 1131 pb e VRSH-B (VRSH-B senso: 5'GCA ACC ATG TCC AAA CAC AAG 3'; VRSH-B antissenso: 5'GTT ATG ACA CTG GTA TAC CAA CC 3') para a amplificação de $1116 \mathrm{pb}$, obedecendo às seguintes condições de ciclagem térmica: $94{ }^{\circ} \mathrm{C}$ por 5 min, seguido de 40 ciclos compostos por $94^{\circ} \mathrm{C}$ em $40 \mathrm{~s}, 49^{\circ} \mathrm{C}$ por $2 \mathrm{~min}$, $72{ }^{\circ} \mathrm{C}$ durante 1 min e uma extensão final a $72{ }^{\circ} \mathrm{C}$ por $7 \mathrm{~min}$. Os produtos amplificados foram visualizados em gel de agarose ${ }^{25}$.

\section{SEQUENCIAMENTO DO GENE G}

Para as amostras que exibiram amplificação para o gene $G$, a purificação do produto RT-PCR foi realizada com o kit comercial QIAquick PCR Purification (QIAGEN, Maryland, EUA) seguindo as instruções do fabricante. $O$ produto purificado foi quantificado para determinar a concentração de DNA e depois utilizado na reação de sequenciamento com o kit Big Dye ${ }^{\circledR}$ terminator Cycle Sequencing v3.1 (Applied Biosystem, Life Technologies, Califórnia, EUA). Posteriormente, as amostras foram submetidas à precipitação com isopropanol e etanol para remover o excesso de bases marcadas não incorporadas na reação. Após a precipitação, os espécimes foram novamente suspensos em formamida altamente deionizada e submetidos à eletroforese por sequenciamento automatizado ABIPrism 3130xl (Applied Biosystem, Foster City, EUA).

\section{ANÁLISE DA SEQUÊNCIA DE NUCLEOTÍDIOS E INFERÊNCIAS FILOGENÉTICAS}

As sequências obtidas do gene $G$ foram montadas usando o software CAP3 ${ }^{26}$, alinhadas com MAFFT v7.22127 e editado com o Geneious v8.1.7 Bioinformatics Suite ${ }^{28}$ e comparado com sequências de outros vírus isolados e disponíveis no banco de genes GenBank, do programa BLAST29.

A análise filogenética foi realizada em três etapas. Primeiramente, foi usado o programa IQ-TREE v1.3.230 para escolher o modelo evolutivo mais apropriado para a realização da análise mais semelhante. Posteriormente, a reconstrução filogenética foi feita no mesmo software IQ-TREE30. Também foi realizado o teste de confiabilidade não paramétrico com 100 cópias pelo método bootstrap e, por fim, o software Fig Tree v1.4.231 foi usado para a edição da árvore filogenética gerada.

\section{NÚMEROS DE ADESÃO DE SEQUÊNCIA NUCLEOTÍDICA}

Os números de acesso GenBank das sequências de nucleotídeos obtidas no presente estudo são MF384372 à MF3844 16 para o gene $G$.

\section{ANÁLISE ESTATÍSTICA}

A análise de resíduos, pelo teste qui-quadrado, foi realizada para avaliar a diferença entre as frequências das infecções por VRSH e a faixa etária, utilizando o software BioEstat v5.0. O resultado $\mathrm{p}<0,05$ foi considerado estatisticamente significante.

\section{APROVAÇÃO NO COMITÊ DE ÉTICA}

A presente investigação seguiu todas as orientações contidas na Resolução CNS n 466/2012 do Conselho Nacional de Ética em Pesquisa (CONEP) e foi aprovada pelo Comitê de Ética em Pesquisa com Seres Humanos do Instituto Evandro Chagas, em 4 de abril de 2016, sob o parecer número 1.476.113.

\section{RESULTADOS}

Foram analisados 1.082 espécimes clínicos de pacientes com diagnóstico clínico de IRA. Desse total, 57 (5,3\%) foram positivos para VRSH pelo qRT-PCR, dos quais 45 (78,9\%) apresentaram efeito citopático.

Considerando a distribuição das amostras positivas por faixa etária, a frequência de infecção por VRSH foi mais expressiva em crianças menores de 4 anos de idade, 38 (66,7\%) amostras, resultado estatisticamente significativo ( $p<0,01$ ), e nas faixas etárias de 5 a 14 anos de idade com cinco (8,8\%) amostras e de 15 a 24 anos com três (5,2\%) não foi encontrada significância estatística ( $p>0,05)$. Enquanto que nas faixas etárias de 25 a 59 anos de idade, com nove $(15,8 \%)$ amostras e idades iguais ou maiores de 60 anos, com duas (3,5\%), a frequência foi estatisticamente significativa $(p<0,05)$ (Tabela 1).

Tabela 1 - Distribuição, por faixa etária, das amostras analisadas para VRSH de pacientes com diagnóstico clínico de IRA atendidos em unidades de saúde dos estados do Acre, Amapá, Amazonas, Pará e Roraima, de janeiro a dezembro de 2015

\begin{tabular}{|c|c|c|c|c|c|}
\hline \multirow{2}{*}{$\begin{array}{l}\text { Faixa etária } \\
\text { (anos) }\end{array}$} & \multicolumn{2}{|c|}{ Positivas } & \multicolumn{2}{|c|}{ Negativas } & \multirow{2}{*}{$p^{*}$} \\
\hline & $\mathrm{N}$ & $\%$ & $\mathrm{~N}$ & $\%$ & \\
\hline $0-4$ & 38 & 66,7 & 386 & 37,7 & $p<0,01$ \\
\hline $5-14$ & 5 & 8,8 & 151 & 14,7 & $p>0,05$ \\
\hline $15-24$ & 3 & 5,2 & 87 & 8,5 & $p>0,05$ \\
\hline $25-59$ & 9 & 15,8 & 269 & 26,2 & $p<0,05$ \\
\hline$\geq 60$ & 2 & 3,5 & 132 & 12,9 & $p<0,05$ \\
\hline Total & 57 & 100,0 & 1.025 & 100,0 & \\
\hline
\end{tabular}

\footnotetext{
* Valor de p na análise de resíduos por teste de qui-quadrado.
} 
Na distribuição entre os Estados, no que se refere à faixa etária, é possível observar uma maior frequência de IRA diagnosticada clinicamente em crianças de 0 a 4 anos de idade (424/1.082), sendo o Pará com 152 (30,6\%) amostras, o Acre com $152(41,1 \%)$ e o Amazonas com 100 (58,8\%); um grande contraste quando comparado com $17(47,2 \%)$ amostras de Roraima e 3 (30,0\%) do Amapá (Tabela 2).

Entre as 57 amostras positivas para VRSH, foi possível determinar os subgrupos virais em 45 (78,9\%) amostras, sendo que em $12(21,1 \%)$ amostras não houve a amplificação do material genético, ou seja, não foi evidenciado banda de interesse. Dessas 45, cinco $(11,1 \%)$ pertenciam ao subgrupo VRSH-A e 40 $(88,9 \%)$ ao subgrupo VRSH-B.

A caracterização do subgrupo viral mostrou que todas as amostras do subgrupo $B$ pertenciam ao genótipo de Buenos Aires (BA), sendo 37 (92,5\%) da linhagem BA9 e três $(7,5 \%)$ da linhagem BA10. As cinco $(100,0 \%)$ amostras do subgrupo A pertenciam ao genótipo de Ontário (ON1) (Figura 1).

As frequências dos genótipos virais identificados foram predominantemente observadas no Amazonas, Acre e Pará. No que se refere à distribuição das amostras positivas (57/1.082) para o VRSH, observou-se que 15 (26,3\%) eram do Acre, 23 (40,4\%) do Amazonas e 19 (33,3\%) do Pará, não havendo casos positivos em Roraima e Amapá (Tabela 3).

Quanto ao perfil de circulação do VRSH, no período de janeiro a dezembro de 2015, a maior frequência de todos os casos ocorreu entre os meses de março a julho (Tabela 4).
Tabela 4 - Distribuição mensal dos casos positivos para VRSH de pacientes com diagnóstico clínico de IRA atendidos em unidades de saúde dos estados do Acre, Amapá, Amazonas, Pará e Roraima, de janeiro a dezembro de 2015

\begin{tabular}{|c|c|c|}
\hline \multirow{2}{*}{ Mês } & \multicolumn{2}{|c|}{ Positividade } \\
\hline & $\mathrm{N}$ & $\%$ \\
\hline Janeiro & 2 & 3,5 \\
\hline Fevereiro & - & - \\
\hline Março & 9 & 15,8 \\
\hline Abril & 11 & 19,3 \\
\hline Maio & 20 & 35,1 \\
\hline Junho & 7 & 12,3 \\
\hline Julho & 6 & 10,5 \\
\hline Agosto & 2 & 3,5 \\
\hline Setembro & - & - \\
\hline Outubro & - & - \\
\hline Novembro & - & - \\
\hline Dezembro & - & - \\
\hline Total & 57 & 100,0 \\
\hline
\end{tabular}

Sinal convencional utilizado: - Dado numérico igual a zero, não resultante de arredondamento.

Tabela 2 - Frequência de distribuição dos casos de IRA, por idade, de pacientes atendidos em unidades de saúde dos estados do Acre, Amapá, Amazonas, Pará e Roraima, de janeiro a dezembro de 2015

\begin{tabular}{|c|c|c|c|c|c|c|c|c|c|c|c|c|}
\hline \multirow{3}{*}{$\begin{array}{l}\text { Faixa etária } \\
\text { (anos) }\end{array}$} & \multicolumn{10}{|c|}{ Estados } & \multirow{2}{*}{\multicolumn{2}{|c|}{ Total }} \\
\hline & \multicolumn{2}{|c|}{ Acre } & \multicolumn{2}{|c|}{ Amapá } & \multicolumn{2}{|c|}{ Amazonas } & \multicolumn{2}{|c|}{ Pará } & \multicolumn{2}{|c|}{ Roraima } & & \\
\hline & $\mathrm{N}$ & $\%$ & $N$ & $\%$ & $N$ & $\%$ & $\mathrm{~N}$ & $\%$ & $\mathrm{~N}$ & $\%$ & $\mathrm{~N}$ & $\%$ \\
\hline $0-4$ & 152 & 41,1 & 3 & 30,0 & 100 & 58,8 & 152 & 30,6 & 17 & 47,2 & 424 & 39,2 \\
\hline $5-14$ & 54 & 14,6 & 4 & 40,0 & 19 & 11,2 & 76 & 15,3 & 3 & 8,3 & 156 & 14,4 \\
\hline $15-24$ & 31 & 8,4 & - & - & 11 & 6,5 & 46 & 9,3 & 2 & 5,6 & 90 & 8,3 \\
\hline $25-59$ & 83 & 22,4 & - & - & 18 & 10,6 & 166 & 33,5 & 11 & 30,6 & 278 & 25,7 \\
\hline$\geq 60$ & 50 & 13,5 & 3 & 30,0 & 22 & 12,9 & 56 & 11,3 & 3 & 8,3 & 134 & 12,4 \\
\hline Total & 370 & 100,0 & 10 & 100,0 & 170 & 100,0 & 496 & 100,0 & 36 & 100,0 & 1.082 & 100,0 \\
\hline
\end{tabular}

Sinal convencional utilizado: - Dado numérico igual a zero, não resultante de arredondamento.

Tabela 3 - Frequência de subgrupos e genótipos de VRSH em amostras de pacientes atendidos em unidades de saúde de três estados da Região Amazônica brasileira, de janeiro a dezembro de 2015

\begin{tabular}{|c|c|c|c|c|c|c|c|c|c|c|}
\hline \multirow{3}{*}{ Estados } & \multicolumn{6}{|c|}{ Subgrupos / Genótipos } & \multirow{2}{*}{\multicolumn{2}{|c|}{ Não genotipadas }} & \multirow{2}{*}{\multicolumn{2}{|c|}{ Total }} \\
\hline & \multicolumn{2}{|c|}{ VRSH-B/BA9 } & \multicolumn{2}{|c|}{ VRSH-B/BA10 } & \multicolumn{2}{|c|}{ VRSH-A/ON1 } & & & & \\
\hline & $\mathrm{N}$ & $\%$ & $\mathrm{~N}$ & $\%$ & $\mathrm{~N}$ & $\%$ & $\mathrm{~N}$ & $\%$ & $\mathrm{~N}$ & $\%$ \\
\hline Pará & 7 & 19,0 & - & - & 5 & 100,0 & 7 & 58,3 & 19 & 33,3 \\
\hline Amazonas & 16 & 43,2 & 3 & 100,0 & - & - & 4 & 33,3 & 23 & 40,4 \\
\hline Acre & 14 & 37,8 & - & - & - & - & 1 & 8,4 & 15 & 26,3 \\
\hline Total & 37 & 100,0 & 3 & 100,0 & 5 & 100,0 & 12 & 100,0 & 57 & 100,0 \\
\hline
\end{tabular}

Sinal convencional utilizado: - Dado numérico igual a zero, não resultante de arredondamento. 
BA09

BA 10

ON
AM/134409/2015 AM/134608/2015 AM/135591/2015 AM/136489/2015

$\mathrm{PA} / 136319 / 2015$

$P A / 136321 / 2015$

AM/134606/2015

$\mathrm{PA} / 135710 / 2015$

B/PA/129512/2014_BA9

AC/135484/2015

$\mathrm{AC} / 135735 / 2015$

AC/135489/2015

AC/134360/2015

AC/134361/2015

$\mathrm{AC} / 134874 / 2015$

$A C / 135555 / 2015$

AC/135658/2015

AC/134693/2015

AM/135072/2015

A $/ 136041 / 2015$

PA/134971/2015

$\mathrm{PA} / 135856 / 20150$

$\mathrm{AC} / 136237 / 2015$

AC/133497/2015

PA/135826/2015

AC/133488/2015

AC/134510/2015

AC/135554/2015

B/PA/124076/2013 BA9

$\mathrm{B} / \mathrm{PA} / 124678 / 2013 \mathrm{BA9}$

$\mathrm{AM} / 134880 / 2 \overline{015}$

$\mathrm{AM} / 134886 / 2015$

$A M / 134888 / 2015$

AM/135068/2015

AM/135760/2015

$\mathrm{AM} / 136430 / 2015$

AM/135074/2015

AM/134406/2015

- $\mathrm{AM} / 135364 / 2015$

AM/134876/20150

$\mathrm{AM} / 135360 / 2015$

AM/135362/2015

AM/134410/2015

$\mathrm{B} / \mathrm{PA} / 124666 / 2013 \mathrm{BA} 10$

$\mathrm{B} / \mathrm{PA} / 123897 / 2013-\mathrm{BA} 10$

HM459889/NG-025-07 BA10

HM459857/NG-010-09 BA2

HM459856/NG-008-09-BA2

AY751117/BE/13159/02 BA

HM459874/NG-045-07 BA8

AB500658 BA8

HM459872/NG-112-06 BA8

DQ227370/BA/495/02 BĀ3

政227381/BA $1441 / 02$ BA1

AB603483/NG-046-02 BA5

AB603480/NG-147-02_BA5

AB603481/NG-137-02-BA5

HM459858/NG-091-03 BA4

HM459864/NG-068-05 BA7

HM459866/NG-102-05-BA7
HM459868/NG-082-07 BA7

M459859/NG-182-03 BA4

4M45863/NG-029-04 BA4

PA/135196/2015

PA/135207/2015

$\mathrm{PA} / 135207 / 2015$

$\mathrm{PA} / 135178 / 2015$

$\mathrm{PA} / 135211 / 2015$

JN257693 ON1

JN257697 NA1

N257694-ON1

อ. $\times 25695 \overline{1}$ NA $\overline{2}$

JX256952 NA2

JX513319 GA $\overline{3}$

JX256964 GA3

FJ391449 GA7

FJ391450- GA7

AF348806 GA 2

EU582178 GA6

EU582178_GA6

HM063448_GA1

FJ804075-GA5

JN257698 GA4

든 FJ804076 GA5

J804081 SAA1

Figura 1 - Árvore filogenética da sequência completa do gene que codifica a glicoproteína G do VRSH dos subgrupos A e B 


\section{DISCUSSÃO}

$\mathrm{Na}$ presente pesquisa, predominou a infecção por casos de VRSH em crianças de 0 a 4 anos de idade $(p<0,01)$, fato comumente relatado e que se deve, entre outros fatores, à suscetibilidade imunológica encontrada em crianças pequenas ${ }^{15,22,32}$.

Durante a investigação, o VRSH não foi detectado no Amapá e em Roraima. Uma justificativa para esse resultado é que, nesses Estados, o tamanho amostral de espécimes clínicos de crianças de 0 a 4 anos de idade foi expressivamente reduzido quando comparado aos demais, sendo que essa faixa etária é a mais afetada pelas infecções por VRSH. Em contraste, as amostras clínicas obtidas no Amazonas, Pará e Acre, que, além de terem sido obtidas em maior quantidade, eram predominantemente de indivíduos de zero a quatro anos de idade.

A maior circulação viral ocorreu do $3^{\circ}$ ao $7^{\circ}$ mês do ano de 2015, período de transição climática na região. Outros estudos mostram que, durante esse período, há um maior índice de infecções pelo VRSH, como os realizados no Brasil ${ }^{33,34}$ e em outros países de clima tropical, como a Colômbia ${ }^{35}$.

Desde o surgimento do genótipo de BA, em 1999, com circulação expressiva global, característica que persiste até hoje, essa cepa é predominante em relação aos outros genótipos do subgrupo B. Acredita-se que isso ocorra devido à duplicação de 60 nucleotídeos na porção C-terminal, o que acumula mutações, fato que pode favorecer a infectividade do VRSH e explicar a circulação expressiva desse genótipo no mundo $36,37,38$.

Este estudo é o primeiro a detectar a circulação do genótipo ON1 no estado do Pará. Esse genótipo viral tem como característica principal a duplicação de 72 nucleotídeos na região C-terminal da glicoproteína $G$, o que pode estar associada a alterações genéticas e assim explicar a expansão global do $\mathrm{ON} 1^{10,39}$.

\section{CONCLUSÃO}

No presente estudo, o subgrupo VRSH-B e o genótipo BA foram os mais frequentes em três Estados da Amazônia brasileira no ano de 2015. O perfil de circulação do VRSH demonstrou um maior pico de infecções durante o período de mudanças naturais de clima, com maior atividade nos meses de março a julho de 2015. $\bigcirc$ vírus foi predominantemente detectado em crianças com idade de 0 a 4 anos. Pela primeira vez foi relatada a circulação de genótipos $\mathrm{ON1}$ no estado do Pará.

\section{APOIO FINANCEIRO}

Apoio financeiro do Conselho Nacional de Desenvolvimento Científico e Tecnológico e do Instituto Evandro Chagas.

\section{CONFLITOS DE INTERESSE}

Os autores declaram que não houve conflitos de interesse.

\section{CONTRIBUIÇÃO DOS AUTORES}

Todos os autores contribuíram com a idealização do estudo, a análise e a interpretação dos dados e com a redação do manuscrito, aprovando a versão final publicada. Declararam-se responsáveis pelo conteúdo integral do artigo, garantindo sua precisão e integridade.

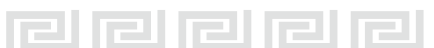

\section{REFERÊNCIAS}

1 Karadag-Oncel E, Ciblak MA, Ozsurekci Y, Badur $S$, Ceyhan M. Viral etiology of influenza-like illnesses during the influenza season between December 2011 and April 2012. J Med Virol. 2014 May;86(5):865-71.

2 Kouni S, Karakitsos P, Chranioti A, Theodoridou M, Chrousos G, Michos A. Evaluation of viral co-infections in hospitalized and non-hospitalized children with respiratory infections using microarrays. Clin Microbiol Infect. 2013 Aug; 19(8):772-7.

3 World Health Organization. A manual for estimating disease burden associated with seasonal influenza [Internet]. Geneva: WHO; 2015 [cited 2017 Oct 5]. Available from: http://apps.who.int/ iris/bitstream/10665/178801/1/9789241549301_ eng.pdf.
4 Fall A, Dia N, Cisse EHAK, Kiori DE, Sarr FD, Sy S, et al. Epidemiology and molecular characterization of human respiratory syncytial virus in Senegal after four consecutive years of surveillance, 2012-2015. PLoS One. 2016 Jun; 11 (6):e0157163.

5 Collins PL, Karron RA. Respiratory syncytial virus and metapneumovirus. In: Knipe DM, Howley PM, editors. Fields virology. 6th ed. Philadelphia: Lippincott Williams \& Wilkins; 2013. p. 1086-123.

6 International Committee on Taxonomy of Viruses. Virus taxonomy: 2015 Release. (EC 47) [Internet]. London: ICTV; 2015 Jul [cited 2017 Oct 5]. Available from: https://talk.ictvonline.org/ taxonomy/p/taxonomy_releases\#fragment- 12227 taxonomy_release_history_panel_release_info. 
7 Peret TC, Hall CB, Schnabel KC, Golub JA, Anderson LJ. Circulation patterns of genetically distinct group $A$ and $B$ strains of human respiratory syncytial virus in a community. J Gen Virol. 1998 Sep;79(Pt 9):2221-9.

8 Venter M, Madhi SA, Tiemessen CT, Schoub BD. Genetic diversity and molecular epidemiology of respiratory syncytial virus over four consecutive seasons in South Africa: identification of new subgroup A and B genotypes. J Gen Virol. 2001 Sep;82(P+ 9):2117-24.

9 Shobugawa $Y$, Saito R, Sano $Y$, Zaraket $H$, Suzuki $Y$, Kumaki A, et al. Emerging genotypes of human respiratory syncytial virus subgroup $A$ among patients in Japan. J Clin Microbiol. 2009 Jul;47(8):2475-82.

10 Eshaghi A, Duvvuri VR, Lai R, Nadarajah JT, Li A, Patel $S N$, et al. Genetic variability of human respiratory syncytial virus $A$ strains circulating in Ontario: a novel genotype with a 72 nucleotide G gene duplication. PLoS One. 2012 Mar;7(3):e32807.

11 Baek YH, Choi EH, Song MS, Pascua PNQ, Kwon HI, Park SJ, et al. Prevalence and genetic characterization of respiratory syncytial virus (RSV) in hospitalized children in Korea. Arch Virol. 2012 Jun; 157(6): 1039-50.

12 Cui G, Zhu R, Qian Y, Deng J, Zhao L, Sun Y, at al. Genetic variation in attachment glycoprotein genes of human respiratory syncytial virus subgroups $A$ and $B$ in children in recent five consecutive years. PLoS One. 2013 Sep;8(9):e75020.

13 Peret TCT, Hall CB, Hammond GW, Piedra PA, Storch GA, Sullender WM, et al. Circulation patterns of group $A$ and $B$ human respiratory syncytial virus genotypes in 5 communities in North America. J Infect Dis. 2000 Jun;181(6): 1891-6.

14 Ren L, Xiao Q, Zhou L, Xia Q, Liu E. Molecular characterization of human respiratory syncytial virus subtype B: a novel genotype of subtype B circulating in China. J Med Virol. 2015 Jan;87(1):1-9.

15 Arnott A, Vong S, Mardy S, Chu S, Naughtin M, Sovann $L$, et al. A study of the genetic variability of human respiratory syncytial virus (HRSV) in Cambodia reveals the existence of a new HRSV group B genotype. J Clin Microbiol. 2011 Sep;49(10):3504-13.

16 Blanc A, Delfraro A, Frabasile S, Arbiza J. Genotypes of respiratory syncytial virus group B identified in Uruguay. Arch Virol. 2005 Mar; 150(3):603-9.

17 Dapat IC, Shobugawa Y, Sano Y, Saito R, Sasaki A, Suzuki $Y$, et al. New genotypes within respiratory syncytial virus group B genotype BA in Niigata, Japan. J Clin Microbiol. 2010 Aug;48(9):3423-7.
18 Trento A, Viegas M, Galiano M, Videla C, Carballal $G$, Mistchenko AS, et al. Natural history of human respiratory syncytial virus inferred from phylogenetic analysis of the attachment (G) glycoprotein with a 60-nucleotide duplication. J Virol. 2006 Dec;80(2):975-84.

19 Hu P, Zheng T, Chen J, Zhou T, Chen Y, Xu X, et al. Alternate circulation and genetic variation of human respiratory syncytial virus genotypes in Chengdu, West China, 2009-2014. J Med Virol. 2017 Jan;89(1):32-40.

20 García O, Martín M, Dopazo J, Arbiza J, Frabasile $S$, Russi J, et al. Evolutionary pattern of human respiratory syncytial virus (subgroup $A$ ): cocirculating lineages and correlation of genetic and antigenic changes in the $G$ glycoprotein. J Virol. 1994 Sep;68(9):5448-59.

21 Melero JA, García-Barreno B, Martínez I, Pringle CR, Cane PA. Antigenic structure, evolution and immunobiology of human respiratory syncytial virus attachment $(G)$ protein. J Gen Virol. 1997 Oct;78(Pt 10):2411-8.

22 Balmaks R, Ribakova I, Gardovska D, Kazaks A. Molecular epidemiology of human respiratory syncytial virus over three consecutive seasons in Latvia. J Med Virol. 2014 Nov;86(11):1971-82.

23 Iwane MK, Farnon EC, Gerber SI. Importance of global surveillance for respiratory syncytial virus. J Infect Dis. 2013 Dec;208 Suppl 3:S165-6.

24 Centers for Disease Control and Prevention. Training course in Real-Time RT-PCR assays for non-Influenza respiratory viruses. São Paulo: Instituto Adolfo Lutz; 2013.

25 Santos MC. Caracterização molecular de cepas do vírus respiratório sincicial isoladas de casos de infecção respiratória aguda na cidade de Belém, Pará, Brasil entre os anos de 2000 a 2006 [dissertação]. Belém (PA): Universidade Federal do Pará, Núcleo de Medicina Tropical; 2006. 79 p.

26 Huang X, Madan A. CAP3: a DNA sequence assembly program. Genome Res. 1999 Sep;9(9):868-77.

27 Katoh K, Misawa K, Kuma K, Miyata T. MAFFT: a novel method for rapid multiple sequence alignment based on fast Fourier transform. Nucleic Acids Res. 2002 Jul;30(14):3059-66.

28 Kearse M, Moir R, Wilson A, Stones-Havas S, Cheung M, Sturrock $S$, et al. Geneious Basic: an integrated and extendable desktop software platform for the organization and analysis of sequence data. Bioinformatics. 2012 Jun;28(12):1647-9.

29 Altschul SF, Madden TL, Schäffer AA, Zhang J, Zhang Z, Miller W, et al. Gapped BLAST and PSI-BLAST: a new generation of protein database search programs. Nucleic Acids Res. 1997 Sep;25(17):3389-402. 
30 Nguyen LT, Schmidt HA, von Haeseler A, Minh BQ. IQ-TREE: a fast and effective stochastic algorithm for estimating maximum-likelihood phylogenies. Mol Biol Evol. 2015 Jan;32(1):268-74.

31 Rambaut A, Drummond A. FigTree: tree figure drawing tool, version 1.2.2. Edinburgh: University of Edinburgh, Institute of Evolutionary Biology; 2008.

32 Gimferrer L, Campins M, Codina MG, Martín MC, Fuentes F, Esperalba J, et al. Molecular epidemiology and molecular characterization of respiratory syncytial viruses at a tertiary care university hospital in Catalonia (Spain) during the 2013-2014 season. J Clin Virol. 2015 May;66:27-32.

33 Bouzas ML, Oliveira JR, Fukutani KF, Borges IC, Barral A, Van der Gucht W, et al. Respiratory syncytial virus $a$ and $b$ display different temporal patterns in a 4-year prospective cross-sectional study among children with acute respiratory infection in a tropical city. Medicine (Baltimore). 2016 Oct;95(41):e5142.

34 Gurgel RQ, Bezerra PGM, Duarte MCMB, Moura $A A ́$, Souza EL, Silva LSS, et al. Relative frequency, possible risk factors, viral codetection rates, and seasonality of respiratory syncytial virus among children with lower respiratory tract infection in Northeastern Brazil. Medicine (Baltimore). 2016 Apr;95(15):e3090.
35 Piñeros JG, Baquero H, Bastidas J, García J, Ovalle $O$, Patiño $C M$, et al. Respiratory syncytial virus infection as a cause of hospitalization in population under 1 year in Colombia. J Pediatr (Rio J). 2013 Nov-Dec;89(6):544-8.

36 Agoti CN, Gitahi CW, Medley GF, Cane PA, Nokes DJ. Identification of group $B$ respiratory syncytial viruses that lack the 60-nucleotide duplication after six consecutive epidemics of total BA dominance at coastal Kenya. Influenza Other Respir Viruses. 2013 Nov;7(6):1008-12.

37 Esposito S, Piralla A, Zampiero A, Bianchini S, Di Pietro G, Scala A, et al. Characteristics and their clinical relevance of respiratory syncytial virus types and genotypes circulating in Northern Italy in five consecutive winter seasons. PLoS One. 2015 Jun;10(6):e0129369.

38 Trento A, Casas I, Calderón A, Garcia-Garcia ML, Calvo C, Perez-Breña P, et al. Ten years of global evolution of the human respiratory syncytial virus $B A$ genotype with 60-nucleotide duplication in the $G$ protein gene. J Virol. $2010 \mathrm{Jul} ; 84(15): 7500-12$.

39 Pierangeli A, Trotta D, Scagnolari C, Ferreri ML, Nicolai A, Midulla F, et al. Rapid spread of the novel respiratory syncytial virus $A$ ONI genotype, central Italy, 2011 to 2013. Euro Surveill. 2014 Jul;19(26): pii $=20843$. 